Supplement of

\title{
Influence of cloud microphysical processes on black carbon wet removal, global distributions, and radiative forcing
}

\section{Jiayu Xu et al.}

Correspondence to: Junfeng Liu (jfliu@ pku.edu.cn)

The copyright of individual parts of the supplement might differ from the CC BY 4.0 License. 

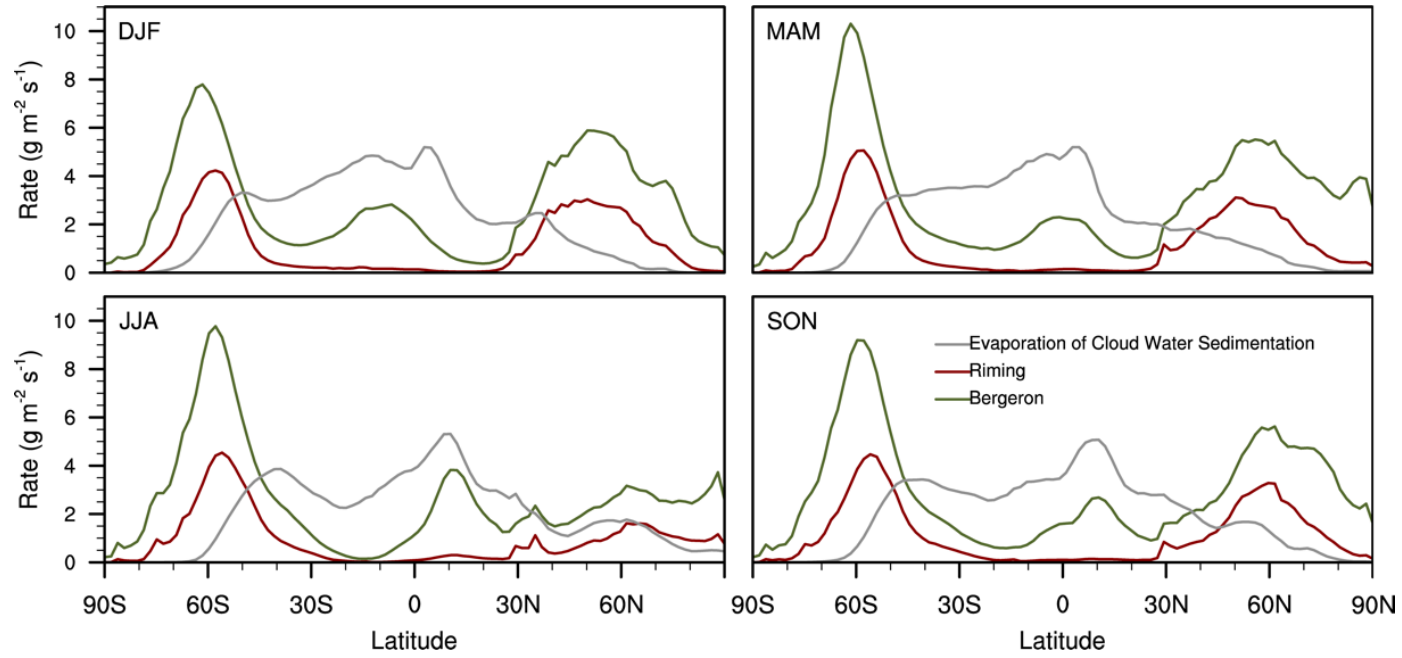

Figure S1. Cloud water column mean conversion rate due to Bergeron, riming, evaporation of cloud water and ice sedimentation, evaporation of cloud process, over four seasons (DJF, MAM, JJA, and SON). 


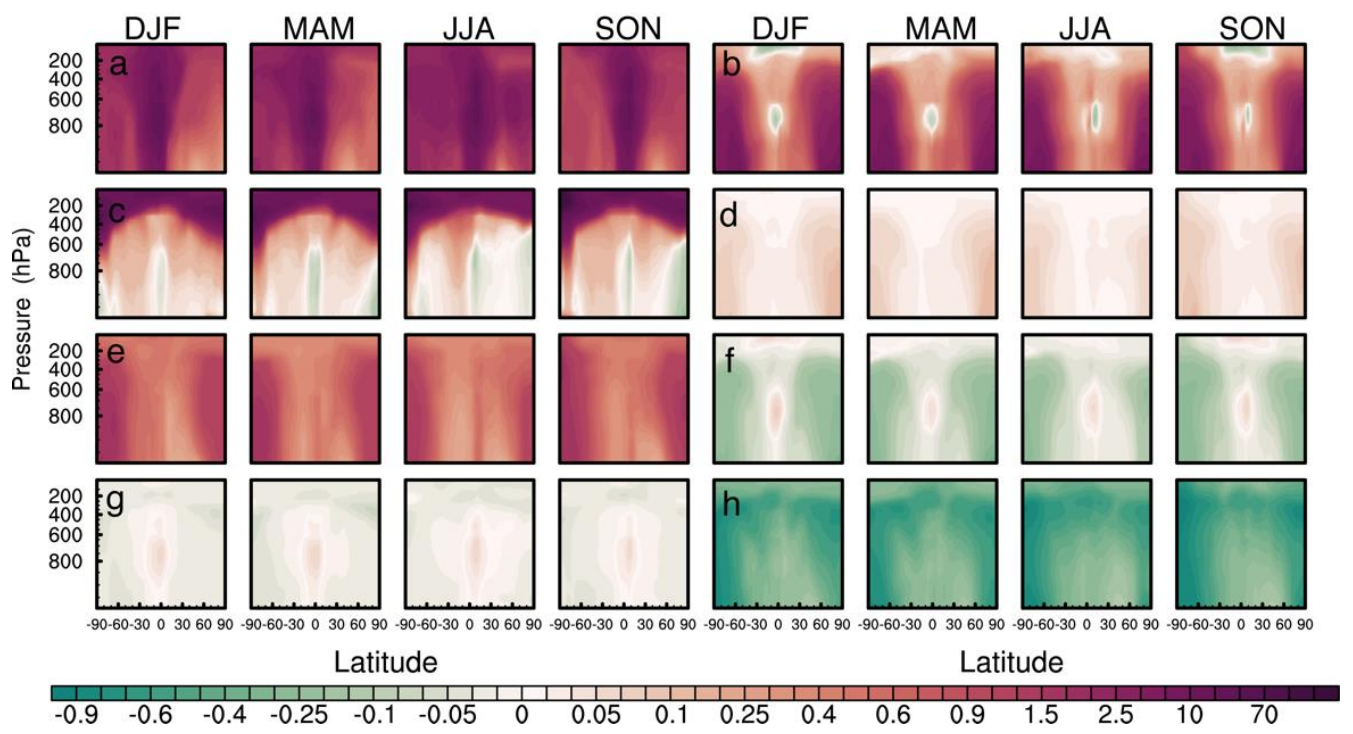

Figure S2. Annual zonal mean fractional changes in BC concentrations relative to BASE in eight sensitivity simulations when the influence of one cloud process on BC is turned off over four seasons (DJF, MAM, JJA, SON). The sensitivity simulations are described in section 2.3, including (a) NO CONVECTION (no convection scavenging), (b) NO CCN (no cloud activation), (c) NO IN (no ice nucleation), (d) NO RIMING (no riming), (e) NO BELOW CLOUD (no below cloud scavenging), (f) NO BEGERON (no Bergeron process), (g) NO CLOUD EVAP (no evaporation of cloud water/ice sedimentation), (h) NO PRECIP EVAP (no evaporation of rain/snow). 


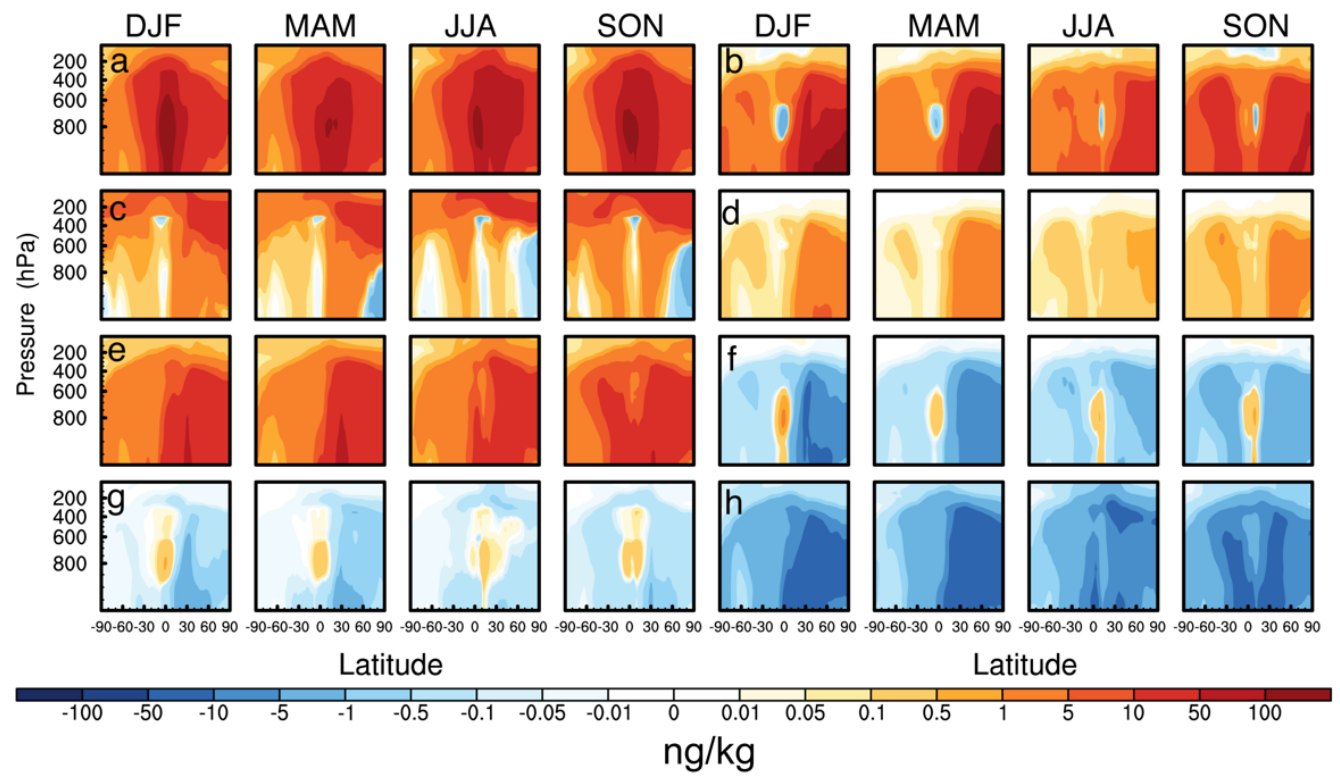

Figure S3. Same as Figure S2, but for absolute changes in BC concentrations for sensitivity simulations relative to BASE 
(a) NO CONVECTION

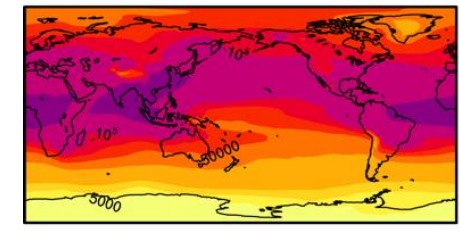

(d) NO RIMING

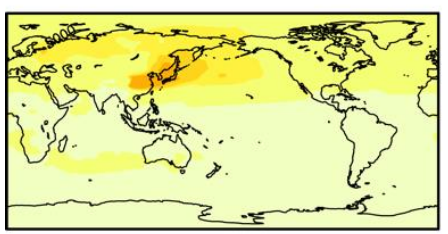

(g) NO CLOUD EVAP

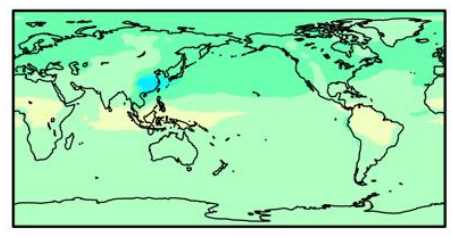

(e) NO BELOW CLOUD

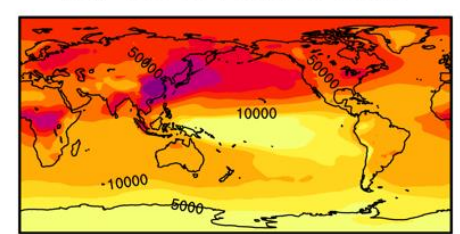

(h) NO PRECIP EVAP

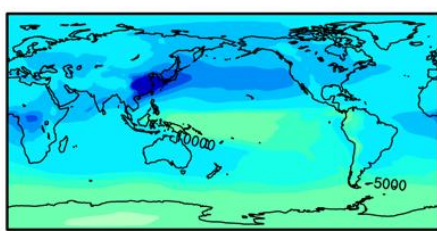

$\begin{array}{lllllllll}-100000 & -50000 & -10000 & -5000 & 0 & 5000 & 10000 & 50000 & 100000\end{array}$

ng $\mathrm{m}^{-2}$ (c) NO IN

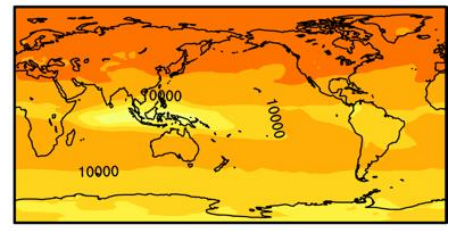

(f) NO BERGERON

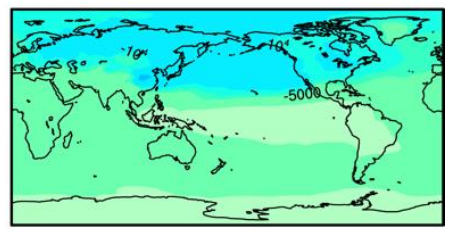

政 
(a) CONVECTION

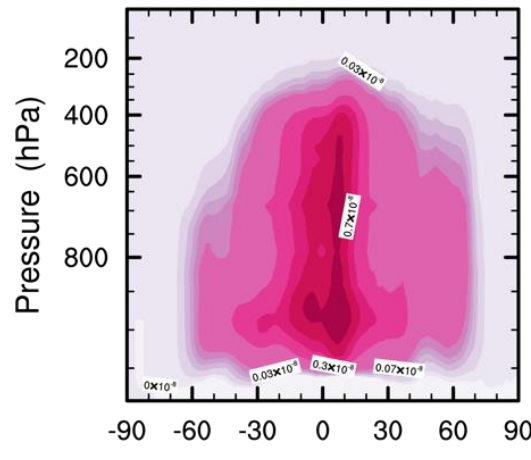

(c) BERGERON

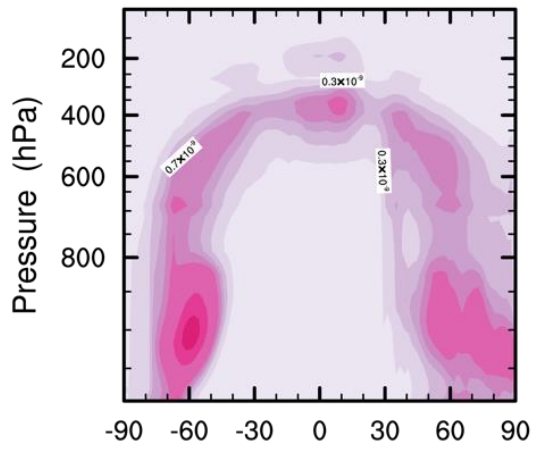

(e) PRECIP EVAP

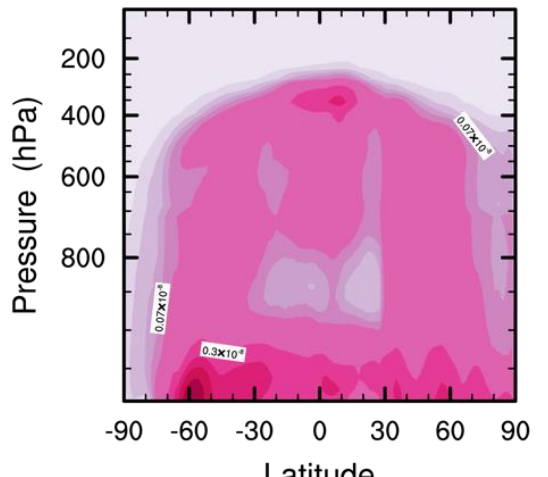

Latitude

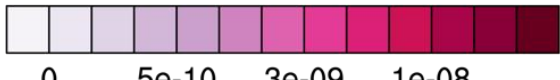

$\mathrm{kg} / \mathrm{kg} / \mathrm{s}$ (b) RIMING

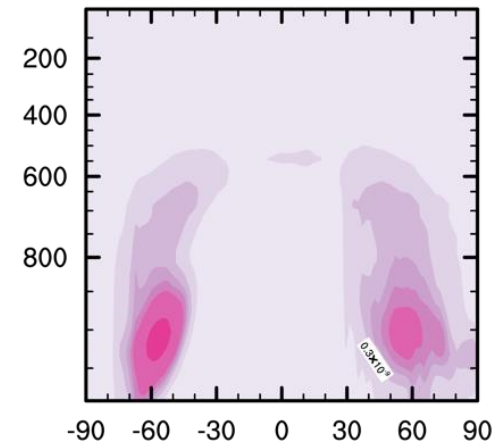

(d) CLOUD EVAP

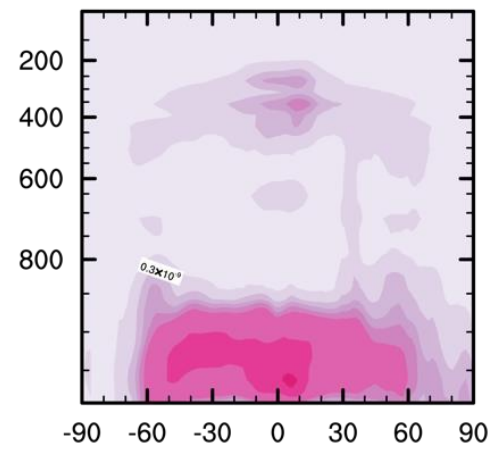

(f) $\mathrm{CCN}$

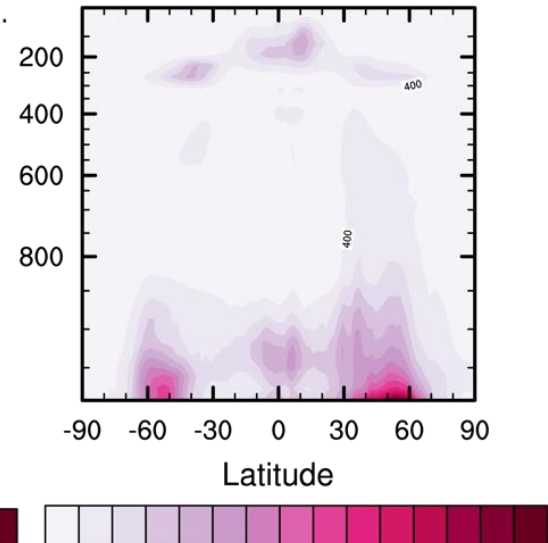

400120020002800360044005200

$1 / \mathrm{kg} / \mathrm{s}$

Figure S5. Annual zonal mean tendencies of six cloud processes including CONVECTION (convection scavenging), RIMING (riming), BEGERON (Bergeron process), CLOUD EVAP (evaporation of cloud water/ice sedimentation), PRECIP EVAP (evaporation of rain/snow), CCN (cloud activation). The former five processes are in unit of $\mathrm{kg} \mathrm{kg}^{-1} \mathrm{~s}^{-1}$, and the latter ones are in unit of $\# \mathbf{k g}^{-1} \mathrm{~s}^{-1}$ 